\title{
EVALUASI KINERJA OPERASI SIMPANG PADA JALAN PASIR KALIKI MENGGUNAKAN SOFTWARE VISSIM
}

\author{
Hansen Wijaya ${ }^{[1]}$ \\ Budi Hartanto Susilo ${ }^{[2]}$ \\ [1] Alumni, Program Studi Teknik Sipil, Fakultas Teknik, Universitas Kristen Maranatha \\ Email: hanswj1221@gmail.com

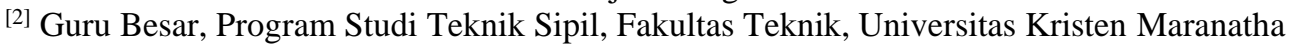 \\ Jl. Prof. Drg. Soeria Sumantri, MPH No. 65 Bandung 40164 \\ Email: budiharsus@yahoo.com
}

\begin{abstract}
ABSTRAK
Kondisi jalan yang lancar memberikan kenyamanan dalam menggunakan kendaraan. Tingginya aktivitas pada pusat-pusat kegiatan menyebabkan kapasitas jalan terlampaui dan menyebabkan kemacetan. Kemacetan yang terjadi mengganggu tingkat kenyamanan dalam berkendara. Kemacetan terjadi akibat konflik yang berada pada persimpangan atau aktifitas yang mengganggu ruas jalan. Jalan Pasir Kaliki memiliki 3 buah simpang berurutan yaitu Simpang Dr. DjunjunanPasir Kaliki, Simpang Dursasana-Pasir Kaliki, dan Simpang Pajajaran-Pasir Kaliki dengan jarak antar simpang yang kurang dari 500 meter. Jalan Pasir Kaliki merupakan akses jalan menuju sekolah, daerah perbelanjaan oleh-oleh, dan bandara, sehingga pada hari dan jam tertentu terjadi kemacetan.

Evaluasi kinerja operasi ketiga simpang pada Jalan Pasir Kaliki dilakukan dengan menggunakan software VisSim dan memberikan solusi alternatif untuk meningkatkan kinerja operasi ketiga simpang tersebut. Lokasi penelitian berada di Simpang Dr. Djunjunan-Pasir Kaliki, Simpang Dursasana-Pasir Kaliki, dan Simpang Pajajaran-Pasir Kaliki. Pengambilan data dilakukan pada jam tersibuk jalan Pasir Kaliki yaitu pukul 14.00-15.00 WIB. Pengambilan data pada ketiga simpang berupa data geometri simpang, data volume kendaraan, data kecepatan kendaraan, data panjang antrean, data waktu siklus lampu lalu lintas. Jenis kendaraan yang dihitung adalah sepeda motor, kendaraan ringan, kendaraan berat.

Kinerja operasi Simpang Dr. Djunjunan-Pasir Kaliki menunjukkan LoS E, kinerja operasi Simpang Dursasana-Pasir Kaliki menunjukkan LoS C, dan kinerja operasi Simpang PajajaranPasir Kaliki menunjukkan LoS D. Dalam rangka meningkatkan kinerja operasi simpang tersebut, maka lampu lalu lintas diberlakukan green wave sehingga menghasilkan kinerja yang lebih baik. Waktu perjalanan untuk melewati ketiga simpang lebih pendek dari sebelumnya, dari 307 detik menjadi 215 detik. Operasi green wave akan lebih efektif bila pada jam tertentu dialihkan. Hasil simulasi perubahan penambahan arus dari Jalan Dr. Radjiman belok ke kanan memberikan hasil sedang.
\end{abstract}

Kata kunci: simpang, kemacetan, panjang antrean, simpang bersinyal, koordinasi simpang bersinyal.

\section{PENDAHULUAN}

Kondisi jalan yang lancar memberikan kenyamanan dalam menggunakan kendaraan. Tingginya aktivitas pada pusat-pusat kegiatan menyebabkan kapasitas jalan terlampaui dan menyebabkan kemacetan. Kemacetan yang terjadi mengganggu tingkat kenyamanan dalam berkendara. Kemacetan terjadi akibat konflik yang berada pada persimpangan atau aktifitas yang mengganggu ruas jalan. Kemacetan terjadi pada saat jam tersibuk pada suatu jalan karena berhubungan dengan akses jalan tersebut. 
Jalan Pasir Kaliki memiliki 3 buah simpang berurutan yaitu Simpang Dr. Djunjunan-Pasir Kaliki, Simpang Dursasana-Pasir Kaliki, dan Simpang Pajajaran-Pasir Kaliki dengan jarak antar simpang yang kurang dari 500 meter. Jalan Pasir Kaliki merupakan akses jalan menuju sekolah, daerah perbelanjaan oleh-oleh, dan bandara, sehingga pada hari dan jam tertentu terjadi kemacetan pada simpang tersebut.

Evaluasi kinerja pada ketiga simpang dilakukan untuk menyikapi kemacetan yang terjadi. Program software VisSim atau Verkehr in Stadten-Simulationsmodell digunakan untuk memodelkan, mensimulasikan, dan memvisualisasikan lalu lintas secara terperinci. Hasil yang dikeluarkan oleh VisSim dapat memperlihatkan kinerja operasi ketiga simpang pada Jalan Pasir Kaliki dan dapat dijadikan acuan untuk dipertimbangkan dalam meningkatkan kinerja ketiga simpang tersebut kedepannya.

Perumusan masalah dalam penelitian ini yakni bagaimana mengkoordinasikan ketiga simpang bersinyal yang berada di Jalan Pasir Kaliki dengan menggunakan software VisSim, apakah dapat memperbaiki tingkat pelayanan ketiga simpang tersebut, dan berapakah waktu perjalanan yang diperlukan untuk melewati ketiga simpang tersebut.

Penelitian ini juga bertujuan untuk mengevaluasi kinerja operasi Simpang Dr. Djunjunan-Pasir Kaliki, Simpang Dursasana-Pasir Kaliki, dan Simpang Pajajaran-Pasir Kaliki dengan menggunakan software VisSim dan memberikan solusi alternatif untuk meningkatkan kinerja operasi Simpang Dr. Djunjunan-Pasir Kaliki, Simpang DursasanaPasir Kaliki, dan Simpang Pajajaran-Pasir Kaliki.

\section{TINJAUAN PUSTAKA}

Persimpangan adalah titik pada jaringan jalan dengan jalan-jalan bertemu dan lintasan-lintasan kendaraan saling berpotongan (Susilo, 2011). Persimpangan jalan dapat diartikan sebagai daerah umum dengan dua jalan atau lebih bergabung atau bersimpang, termasuk jalan dan fasilitas tepi jalan untuk pergerakan lalu lintas di dalamnya (AASHTO, 2001). Menurut Kamus Besar Bahasa Indonesia (KBBI), persimpangan adalah suatu jalan atau sebagainya yang berkelok atau bercabang.

Simpang bersinyal adalah simpang yang memiliki Alat Pemberi Isyarat Lalu Lintas (APILL). Pengguna jalan dapat melewati simpang sesuai instruksi APILL. Unsurunsur penting dalam simpang bersinyal adalah lampu lalu lintas, kapasitas, dan tingkat pelayanan. Simpang bersinyal diharapkan mampu meningkatkan tingkat keamanan dan kenyamanan dalam berkendara. 
Koordinasi sinyal diantara persimpangan diperlukan untuk mengoptimalkan kapasitas jalan, dengan adanya koordinasi sinyal diharapkan tundaan (delay) yang terjadi dapat berkurang dan mempersingkat waktu perjalanan. Kendaraan yang telah bergerak melewati satu simpang diusahakan tidak terkena sinyal merah pada simpang berikutnya, sehingga dapat terus berjalan dengan kecepatan normal. Sistem koordinasi simpang bersinyal merupakan salah satu indikasi dari manejemen transportasi yang memberikan keuntungan berupa biaya operasional (Juni et al., 2018).

Menurut Taylor dkk (1996), koordinasi simpang bersinyal merupakan salah satu jalan untuk mengurangi tundaan dan antrian serta menghemat waktu perjalanan. Adapun prinsip koordinasi simpang bersinyal menurut Taylor sebagai berikut:

1. waktu siklus sinyal pada tiap simpang diusahakan sama, hal ini untuk mempermudah menentukan selisih nyala sinyal hijau dari satu simpang ke simpang lainnya;

2. pola pengaturan simpang yang digunakan adalah fixed time signal, karena koordinasi sinyal dilakukan berlanjut seperti Gambar 1 .

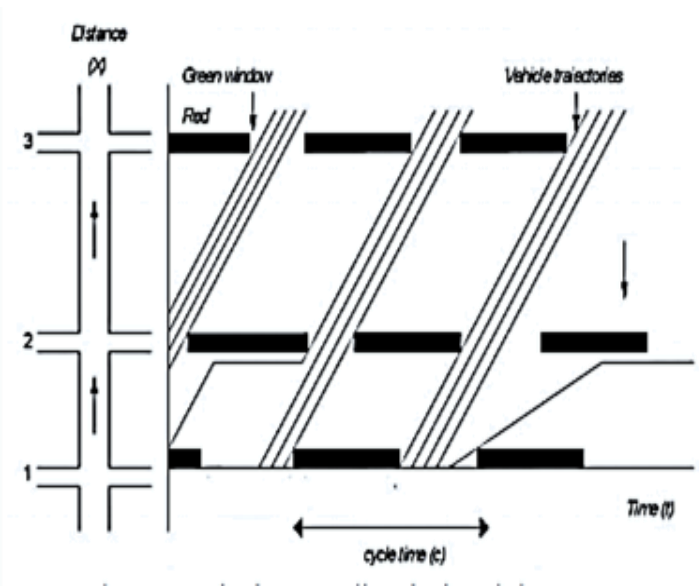

Gambar 1 Prinsip Koordinasi Sinyal dan Green Wave Sumber: Taylor dkk (1996)

Untuk mengkoordinasikan beberapa sinyal, diperlukan beberapa syarat yang harus dipenuhi (McShane dan Roess, 1990), yaitu:

1. jarak antar simpang yang dikoordinasikan tidak lebih dari 800 meter, jika lebih dari 800 meter maka koordinasi sinyal tidak akan efektif lagi;

2. semua sinyal harus mempunyai panjang waktu siklus (circle time) yang sama;

3. umumnya digunakan pada jaringan jalan utama (arteri, kolektor) dan juga dapat digunakan untuk jaringan jalan yang berbentuk grid;

4. terdapat sekelompok kendaraan (platoon) sebagai akibat lampu lalu lintas di bagian hulu. 


\section{METODOLOGI PENELITIAN}

Penelitian ini dilakukan di Kota Bandung, pada simpang bersinyal di Jalan Pasir Kaliki. Waktu penelitian dilakukan pada hari Sabtu saat jam sibuk (volume lalu lintas maksimum). Pengambilan data dilakukan pada siang hari pukul 14.00 - 15.00 WIB. Adapun diagram alir penelitian dapat dilihat pada Gambar 2.

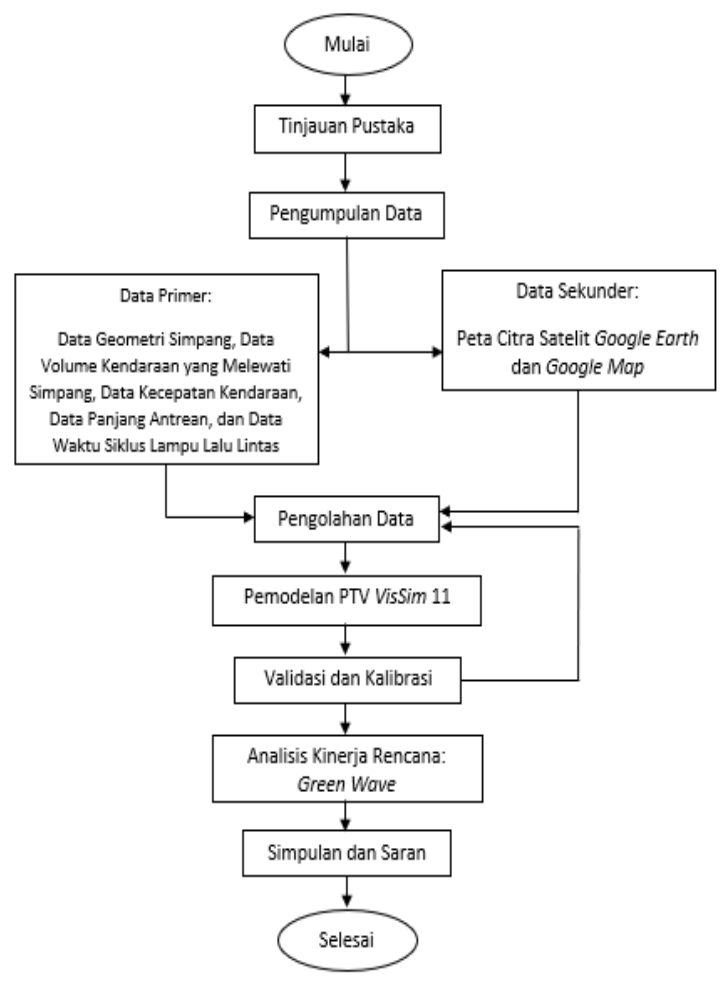

Gambar 2 Diagram Alir Penelitian

\section{HASIL DAN PEMBAHASAN}

Hasil pengambilan data geometri simpang untuk Jalan Dr. Djunjunan dapat dilihat pada Tabel 1, untuk Jalan Pasteur dapat dilihat pada Tabel 2, untuk Jalan Sukajadi dapat dilihat pada Tabel 3, untuk Jalan Pasir Kaliki dapat dilihat pada Tabel 4, untuk Jalan Dursasana dapat dilihat pada Tabel 5, untuk Jalan Dr. Rajiman dapat dilihat pada Tabel 6, untuk Jalan Pajajaran (oneway) dapat dilihat pada Tabel 7, untuk Jalan Pajajaran (Husein) dapat dilihat pada Tabel 8.

Tabel 1 Ukuran Geometri Jalan Dr. Djunjunan

\begin{tabular}{|c|c|c|c|}
\hline \multirow{2}{*}{ Arah } & Lajur 1 Kanan & Lajur 2 Tengah & Lajur 3 Kiri \\
\hline & & (meter) & \\
\hline
\end{tabular}




\begin{tabular}{llll}
\hline Mendekati Simpang & 3,2 & 4,5 & 3,5 \\
Menjauhi Simpang & 3,5 & 3,5 & 3,5 \\
\hline
\end{tabular}

Tabel 2 Ukuran Geometri Jalan Pasteur

\begin{tabular}{ccccc}
\hline \multirow{2}{*}{ Arah } & Lajur 1 Kanan & Lajur 2 Tengah & Lajur 3 Tengah & Lajur 4 Kiri \\
\cline { 2 - 5 } & \multicolumn{3}{c}{ (meter) } \\
\hline Mendekati Simpang & 3,0 & 3,6 & 3,6 & 2,8 \\
Menjauhi Simpang & 3,0 & 3,0 & - & - \\
\hline
\end{tabular}

Tabel 3 Ukuran Geometri Jalan Sukajadi

\begin{tabular}{cccccc}
\hline \multirow{2}{*}{ Arah } & $\begin{array}{c}\text { Lajur 1 } \\
\text { Kanan }\end{array}$ & $\begin{array}{c}\text { Lajur 2 } \\
\text { Tengah }\end{array}$ & $\begin{array}{c}\text { Lajur 3 } \\
\text { Tengah }\end{array}$ & $\begin{array}{c}\text { Lajur 4 } \\
\text { Tengah }\end{array}$ & $\begin{array}{c}\text { Lajur 5 } \\
\text { Kiri }\end{array}$ \\
\cline { 2 - 6 } (meter) \\
\hline Menjauhi Simpang & 2,8 & 2,8 & 2,8 & 2,6 & 2,6 \\
\hline
\end{tabular}

Tabel 4 Ukuran Geometri Jalan Pasir Kaliki

\begin{tabular}{|c|c|c|}
\hline \multirow{2}{*}{ Arah } & Lajur 1 Kanan & Lajur 2 Kiri \\
\hline & \multicolumn{2}{|c|}{ (meter) } \\
\hline Mendekati Simpang & 3,2 & 3,2 \\
\hline Menjauhi Simpang & 3,2 & 3,2 \\
\hline
\end{tabular}

Tabel 5 Ukuran Geometri Jalan Dursasana

\begin{tabular}{ccc}
\hline \multirow{2}{*}{ Arah } & \multicolumn{2}{c}{ Lajur 1 Kanan Lajur 2 Kiri } \\
\cline { 2 - 3 } & \multicolumn{3}{c}{ (meter) } \\
\hline Mendekati Simpang & 3,0 & 3,0 \\
\hline
\end{tabular}

Tabel 6 Ukuran Geometri Jalan Dr. Rajiman

\begin{tabular}{cc}
\hline \multirow{2}{*}{ Arah } & Lajur 1 \\
\cline { 2 - 2 } & (meter) \\
\hline Mendekati Simpang & 3,5 \\
Menjauhi Simpang & 3,5 \\
\hline
\end{tabular}

Tabel 7 Ukuran Geometri Jalan Pajajaran (oneway)

\begin{tabular}{ccccc}
\hline \multirow{2}{*}{ Arah } & Lajur 1 Kanan & Lajur 2 Tengah & Lajur 3 Tengah & Lajur 4 Kiri \\
\cline { 2 - 5 } & 4,0 & 4,0 & 4,0 & 4,0 \\
\hline Mendekati Simpang & 4,0 & (meter) \\
\hline
\end{tabular}

Tabel 8 Ukuran Geometri Jalan Pajajaran (Husein)

\begin{tabular}{|c|c|c|}
\hline \multirow{2}{*}{ Arah } & Lajur 1 Kanan & Lajur 2 Kiri \\
\hline & \multicolumn{2}{|c|}{ (meter) } \\
\hline Mendekati Simpang & 4,0 & 4,0 \\
\hline Menjauhi Simpang & 4,0 & 4,0 \\
\hline
\end{tabular}

Hasil pengambilan data kecepatan kendaraan yang sudah dikonversi dapat dilihat pada Tabel 9.

Tabel 9 Kecepatan Kendaraan

\begin{tabular}{cccc}
\hline \multirow{2}{*}{ Lokasi } & SM & KR & KR \\
\cline { 2 - 3 } & & $(\mathrm{km} / \mathrm{jam})$ & \\
\hline
\end{tabular}




\begin{tabular}{llcc}
\hline Jl. Dr. Djunjunan & 61,68 & 46,21 & 45,17 \\
Jl. Pasteur & 43,49 & 43,96 & 44,45 \\
Jl. Dr. Rajiman & 62,84 & 46,64 & 0 \\
Jl. Dursasana & 57,75 & 49,63 & 0 \\
Jl. Pajajaran & 60,88 & 46,19 & 44,70 \\
Jl. Pasir Kaliki & 61,72 & 47,02 & 46,41 \\
\hline
\end{tabular}

Hasil pengambilan data volume kendaraan dapat dilihat pada Tabel 10 dan arah pergerakan kendaraan dapat dilihat pada Tabel 11.

Tabel 10 Volume Kendaraan

\begin{tabular}{lcccc}
\hline \multicolumn{1}{c}{ Lokasi } & Volume & SM & KR & KR \\
\hline J1. Dr. Djunjunan & 2874 & 1648 & 1188 & 38 \\
J1. Pasteur & 4857 & 2634 & 2189 & 34 \\
Jl. Dr. Rajiman & 360 & 260 & 100 & 0 \\
J1. Dursasana & 1588 & 1172 & 416 & 0 \\
J1. Pajajaran & 2019 & 1300 & 688 & 3 \\
J1. Pasir Kaliki & 3994 & 2316 & 1668 & 10 \\
\hline
\end{tabular}

Tabel 11 Pergerakan Kendaraan

\begin{tabular}{lccc}
\hline \multicolumn{1}{c}{ Lokasi } & Kiri & Kanan & Lurus \\
\hline Jl. Dr. Djunjunan & 1010 & 674 & 1190 \\
Jl. Pasteur & 664 & 2941 & 1252 \\
Jl. Dr. Rajiman & 360 & 0 & 0 \\
Jl. Dursasana & 693 & 280 & 615 \\
Jl. Pajajaran & 668 & 0 & 1351 \\
Jl. Pasir Kaliki & 631 & 927 & 2436 \\
\hline
\end{tabular}

Hasil pengambilan data waktu siklus lampu lalu lintas Simpang Dr. DjunjunanPasir Kaliki dapat dilihat pada Tabel 12, Simpang Dursasana-Pasir Kaliki dapat dilihat pada Tabel 13, Simpang Pajajaran-Pasir Kaliki dapat dilihat pada Tabel 14.

Tabel 12 Waktu Siklus Lampu Lalu Lintas Simpang Dr. Djunjunan-Pasir Kaliki

\begin{tabular}{clccccc}
\hline \multirow{2}{*}{ Fase } & \multicolumn{1}{c}{ Lokasi } & Hijau & Kuning & Merah & $\begin{array}{c}\text { Merah - } \\
\text { Kuning }\end{array}$ & $\begin{array}{c}\text { Waktu } \\
\text { Siklus }\end{array}$ \\
\cline { 2 - 6 } & \multicolumn{7}{c}{ (detik) } \\
\hline 1 & $\begin{array}{l}\text { Jl. Dr. Djunjunan } \\
\text { (kanan dan lurus) }\end{array}$ & 45 & 2 & 196 & 2 & 245 \\
2 & $\begin{array}{l}\text { Jl. Dr. Djunjunan } \\
\text { (lurus) }\end{array}$ & 80 & 2 & 161 & 2 & 245 \\
3 & $\begin{array}{l}\text { Jl. Pasteur } \\
\text { (lurus) }\end{array}$ & 147 & 2 & 94 & 2 & 245 \\
4 & $\begin{array}{l}\text { Jl. Pasteur } \\
\text { (lurus dan kanan) }\end{array}$ & 112 & 2 & 129 & 2 & 245 \\
5 & Jl. Pasir Kaliki & 41 & 2 & 200 & 2 & 245 \\
\hline
\end{tabular}

Tabel 13 Waktu Siklus Lampu Lalu Lintas Simpang Dursasana-Pasir Kaliki

\begin{tabular}{|c|c|c|c|c|c|c|}
\hline Fase & Lokasi & Hijau & Kuning & Merah & $\begin{array}{l}\text { Merah - } \\
\text { Kuning }\end{array}$ & $\begin{array}{l}\text { Waktu } \\
\text { Siklus }\end{array}$ \\
\hline
\end{tabular}




\begin{tabular}{|c|c|c|c|c|c|c|}
\hline \multirow[b]{2}{*}{1} & \multirow[b]{2}{*}{$\begin{array}{l}\text { Jl. Dr. Rajiman - } \\
\text { Jl. Dursasana }\end{array}$} & \multicolumn{5}{|c|}{ (detik) } \\
\hline & & 22 & 2 & 28 & 2 & 54 \\
\hline 2 & Jl. Pasir Kaliki & 24 & 2 & 26 & 2 & 54 \\
\hline
\end{tabular}

Tabel 14 Waktu Siklus Lampu Lalu Lintas Simpang Pajajaran-Pasir Kaliki

\begin{tabular}{clccccc}
\hline \multirow{2}{*}{ Fase } & \multicolumn{1}{c}{ Lokasi } & Hijau & Kuning & Merah & $\begin{array}{c}\text { Merah - } \\
\text { Kuning }\end{array}$ & $\begin{array}{c}\text { Waktu } \\
\text { Siklus }\end{array}$ \\
\cline { 2 - 6 } & & & & (detik) & & \\
\hline 1 & Jl. Pajajaran & 30 & 2 & 66 & 2 & 100 \\
2 & $\begin{array}{l}\text { Jl. Pasir Kaliki } \\
\text { (kanan ke Husein) }\end{array}$ & 30 & 2 & 66 & 2 & 100 \\
3 & $\begin{array}{l}\text { Jl. Pasir Kaliki } \\
\text { (oneway) }\end{array}$ & 28 & 2 & 68 & 2 & 100 \\
\hline
\end{tabular}

Setelah data yang diperlukan terkumpul, dilanjutkan dengan melakukan pemodelan menggunakan software VisSim. Langkah-langkah memodelkan menggunakan software VisSim:

1. Buka aplikasi VisSim, pilih New.

2. Masukan Background Image.

3. Menggambar jaringan jalan menggunakan Link.

4. Menyambungkan jaringan jalan dengan Connector Link.

5. Menambahkan jenis kendaraan.

6. Mendistribusikan kendaraan.

7. Mengelompokan jenis kendaraan.

8. Mengatur komposisi dan kecepatan kendaraan.

9. Memasukan kendaraan dan volume kendaraan.

10. Mengatur pergerakan kendaraan.

11. Memasukan data waktu siklus lampu lalu lintas.

12. Melakukan kalibrasi pemodelan.

13. Memunculkan data output.

Hasil output kondisi existing dapat dilihat pada Tabel 15.

Pemodelan solusi alternatif berupa koordinasi simpang bersinyal (green wave). Koordinasi waktu siklus lampu lalu lintas dapat dilihat pada Gambar 3. Koordinasi simpang bersinyal akan menyesuaikan dengan waktu siklus lampu lalu lintas yang sudah ada, tapi juga dapat berubah sesuai dengan kebutuhannya.

Tabel 15 Output Kondisi Existing

\begin{tabular}{lcccc}
\multicolumn{1}{c}{ Simpang } & QLenMax & LoS & Vehicle Delay & Stop Delay \\
\hline J1. Dr. Djunjunan & 402,3 & E & 64,44 & 47,79 \\
J1. Dursasana & 297,8 & C & 25,79 & 13,76
\end{tabular}




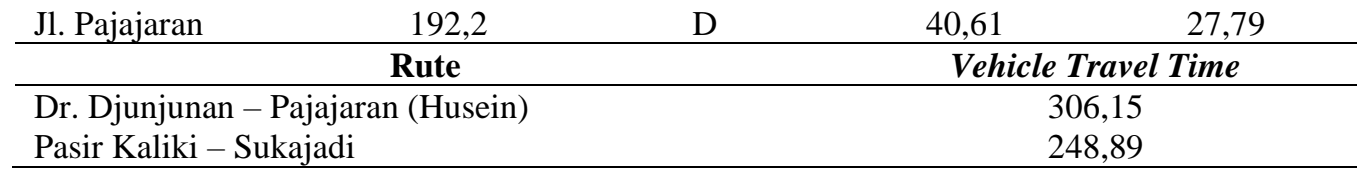

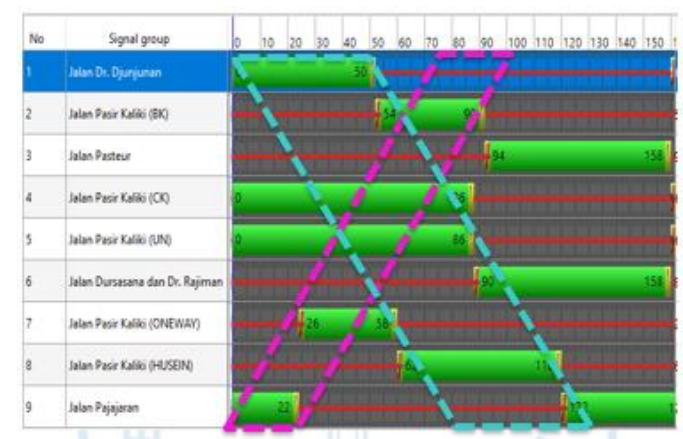

Gambar 3 Koordinasi Waktu Siklus

Garis putus-putus warna biru menunjukan alur koordinasi lampu lalu lintas dari rute Jalan Dr. Djunjunan menuju Jalan Pajajaran (Husein), yaitu nomor 1-4-8. Garis putus-putus warna merah muda menunjukan alur koordinasi lampu lalu lintas dari rute Jalan Pasir Kaliki menuju Jalan Sukajadi, yaitu 9-5-2. Parameter yang digunakan untuk mendesain green wave adalah jarak antar simpang dan kecepatan. Kemiringan garis putus-putus biru dan merah muda tergantung dari kecepatan kendaraan yang beroperasi. Garis putus-putus biru dan merah muda juga tidak selalu membentuk garis lurus karena bergantung pada kecepatan dan jarak.

Kecepatan rata-rata yang didesain pada model adalah sebesar $40 \mathrm{~km} / \mathrm{jam}$ untuk dapat melewati ketiga simpang dengan lampu bewarna hijau (green wave). Kecepatan 40 $\mathrm{km} / \mathrm{jam}$ diasumsikan adalah kecepatan yang mampu ditempuh oleh kendaraan ringan (KR), kendaraan berat (KB), dan sepeda motor (SM) pada saat Jalan Pasir Kaliki dalam kondisi lancar walaupun ada hambatan samping berupa naik turun penumpang angkutan umum ataupun kendaraan yang keluar masuk dari pertokoan atau bangunan di sepanjang Jalan Pasir Kaliki. Kecepatan yang didesain ini terjadi apabila keadaan jalan lancar dan memungkinkan kendaraan bergerak dengan kecepatan $40 \mathrm{~km} / \mathrm{jam}$ atau dapat dikatakan bahwa kecepatan $40 \mathrm{~km} / \mathrm{jam}$ adalah kecepatan maksimal yang direncanakan untuk melewati ketiga simpang dengan lampu bewarna hijau (green wave). Hasil output kondisi alternatif dapat dilihat pada Tabel 16.

Tabel 16 Output Kondisi Alternatif

\begin{tabular}{lcccc}
\hline \multicolumn{1}{c}{ Simpang } & QLenMax & LoS & Vehicle Delay & Stop Delay \\
\hline Jl. Dr. Djunjunan & 272,4 & E & 62,63 & 48,95 \\
Jl. Dursasana & 187,2 & C & 22,44 & 16,08 \\
Jl. Pajajaran & 271,26 & D & 45,26 & 35,38 \\
\hline
\end{tabular}

Evaluasi Kinerja Operasi Simpang Pada Jalan Pasir Kaliki Menggunakan Software VisSim (Hansen Wijaya, Budi Hartanto Susilo) 


\begin{tabular}{lc}
\hline \multicolumn{1}{c}{ Rute } & Vehicle Travel Time \\
\hline Dr. Djunjunan - Pajajaran (Husein) & 243,60 \\
Pasir Kaliki - Sukajadi & 151,27 \\
\hline
\end{tabular}

Perbandingan kondisi existing dan kondisi alternatif untuk panjang antrean (QLenMax) dapat dilihat pada Tabel 17, untuk tingkat pelayanan $(L o S)$ dapat dilihat pada Tabel 18, untuk tundaan perjalanan (Vehicle Delay) pada Tabel 19, untuk tundaan henti (Stop Delay) pada Tabel 20, dan untuk waktu perjalanan (Vehicle Travel Time) pada Tabel 21.

Tabel 17 Perbandingan Panjang Antrean

\begin{tabular}{lcc}
\hline \multicolumn{1}{c}{ Skenario } & Existing & Alternatif \\
\cline { 2 - 3 } & \multicolumn{2}{c}{ (meter) } \\
\hline Jl. Dr. Djunjunan & 402,3 & 272,4 \\
Jl. Dursasana & 297,8 & 187,2 \\
Jl. Pajajaran & 192,2 & 271,2 \\
\hline
\end{tabular}

Tabel 18 Perbandingan Tingkat Pelayanan

\begin{tabular}{lcc}
\hline \multicolumn{1}{c}{ Skenario } & Existing & Alternatif \\
\hline J1. Dr. Djunjunan & E & E \\
J1. Dursasana & C & C \\
Jl. Pajajaran & D & D \\
\hline
\end{tabular}

Tabel 19 Perbandingan Tundaan Perjalanan

\begin{tabular}{lcc}
\hline \multicolumn{1}{c}{ Skenario } & Existing & Alternatif \\
\cline { 2 - 3 } & \multicolumn{2}{c}{ (detik) } \\
\hline Jl. Dr. Djunjunan & 64,44 & 62,63 \\
Jl. Dursasana & 25,79 & 22,44 \\
Jl. Pajajaran & 40,61 & 45,26 \\
\hline
\end{tabular}

Tabel 20 Perbandingan Tundaan Henti

\begin{tabular}{lcc}
\hline \multicolumn{1}{c}{ Skenario } & Existing & Alternatif \\
\cline { 2 - 3 } & \multicolumn{2}{c}{ (detik) } \\
\hline Jl. Dr. Djunjunan & 47,79 & 48,95 \\
J1. Dursasana & 13,76 & 16,08 \\
J1. Pajajaran & 27,79 & 35,38 \\
\hline
\end{tabular}

Tabel 21 Perbandingan Waktu Perjalanan

\begin{tabular}{lcc}
\hline \multicolumn{1}{c}{ Skenario } & Existing & Alternatif \\
\cline { 2 - 3 } & \multicolumn{2}{c}{ (detik) } \\
\hline $\begin{array}{l}\text { Dr. Djunjunan - Pajajaran } \\
\text { (Husein) }\end{array}$ & 306,15 & 243,60 \\
Pasir Kaliki - Sukajadi & 248,89 & 151,27 \\
\hline
\end{tabular}

\section{KESIMPULAN DAN SARAN}

\subsection{Kesimpulan}

1. Jalan Pasir Kaliki memiliki 3 buah simpang bersinyal yang berdekatan dengan jarak antar simpang 405 meter dan 267 meter. Kinerja operasi Simpang Dr. Djunjunan-Pasir 
Kaliki menunjukkan $L o S$ E dengan tundaan henti sebesar 48 detik, panjang antrean 402,3 meter dan tundaan perjalanan sebesar 65 detik. Kinerja operasi Simpang Dursasana-Pasir Kaliki menunjukkan $\operatorname{LoS} \mathrm{C}$ dengan tundaan henti sebesar 14 detik, panjang antrean 297,8 meter dan tundaan perjalanan sebesar 26 detik. Kinerja operasi Simpang Pajajaran-Pasir Kaliki menunjukkan LoS D dengan tundaan henti sebesar 28 detik, panjang antrean 192,2 meter dan tundaan perjalanan sebesar 41 detik.

2. Peningkatan kinerja operasi simpang dapat dilakukan dengan koordinasi sinyal lampu lalu lintas sehingga menghasilkan kinerja yang lebih baik. Waktu perjalanan untuk melewati ketiga simpang dari sebelumnya 307 detik menjadi 215 detik.

\subsection{Saran}

Sebelum dilakukan perubahan menjadi operasi green wave, perlu dilakukan studi dari aspek pertambahan volume, simulasi arus lalu lintas, dan perhitungan untung rugi yang diperhitungkan dengan waktu perjalanan.

\section{DAFTAR PUSTAKA}

1. AASHTO, 2001, A Policy on Geometric Design of Highways dan Streets, American Association of State Highway and Transportation Officials.

2. Departemen Pekerjaan Umum, 1997, Manual Kapasitas Jalan Indonesia (MKJI), Direktorat Jenderal Bina Marga, Jakarta.

3. Hobbs, F.D., 1995, Perencanaan dan Teknik Lalu-lintas, Edisi kedua, Gadjah Mada University Press.

4. Juni, V. N., Kasus, S., Dan, J. R., Kirono, J. C., Puspasari, N., \& Handayani, N., 2018, Kata Kunci: Simpang Bersinyal, Waktu Siklus, Persimpangan. 6 (1), 109-123.

5. Mc. Shane, 1990, Traffic Engginerring, Prentice Hall, New Jersey.

6. PTV Vission, 2018, PTV VISSIM 11 User Manual, PTV AG, Karlsruhe, Jerman.

7. Susilo, B. H., 2011, Rekayasa Lalu Lintas, Penerbit Universitas Trisakti, Jakarta.

8. Taylor dkk., 1996, Understanding Traffic System, Aldershot, Inggris.

9. Zein dkk, 2010, Analisis dan Koordinasi Sinyal Antar Simpang Pada Ruas Jalan Diponegoro Surabaya, Tugas Akhir- RC09 1380, Jurusan Teknik Sipil Institut Teknologi Sepuluh Nopember. Surabaya. 